and so bringing a desirable object, otherwise inaccessible, within reach.

Since the Makapansgat grey breccia has furnished various other illustrations of this cavity-exploring ability on the part of these predatory employers of bone bludgeons and horn-core daggers, a specimen like this makes it highly probable that these protohuman creatures had also made the conceptual leap chimpanzees can make of putting two things together to extend their reach; and thus, of improving the penetrating power of elongated objects such as sticks and so turning them into spears by capping their ends with hollow horns. The recent discovery of Kafuan stone artefacts and australopithecine remains in the pink breccia overlying the grey breccia at Makapansgat has also been the subject of report (see Nature, $175,16 ; 1955$, and 176,$170 ; 1955)$; they therefore possessed the means of shaping the ends of sticks. 1 Buckland, Rev. W., Phit. Trans. Roy. Soc., 112, 171 (1822). Zapfe,
H., Palaeonbiologica, , 111 (1938).
' Hughes, Alun R., S. Afr. J. Sci., 51, 156 (1954); Amer. J. Phys.
Anthrop., 12, n.8.4, 467 (1954). Dart, Raymond A., Amer. Anthrop., 58, 40 (1956).

\title{
INFLUENCE OF LIGHT ON PLANT GROWTH
}

\section{A} JOINT symposium on the influence of light on plant growth arranged by the Association of Applied Biologists and the Horticultural Education Association was held in the British Museum (Natural History) on February 22. The morning session was devoted to a discussion of certain aspects of photoperiodism in plants. The photoperiodic control of flowering in short-day plants was reviewed by Dr. D. Vince (University of Reading), with special reference to the chrysanthemum. In short-day plants, providing that they have first been exposed to light of high intensity, flowering is determined by exposure to dark periods of more than a certain critical length. During the dark period reactions occur that promote flowering, which may be inhibited or reduced by light of low intensity, by the application of auxin to the leaves, and by low temperatures. Red light $(6550$ A.) is most effective in suppressing flowering in several species (including chrysanthemum) when given in the middle of an inductive dark period; the effect of red light can be annulled by later exposure to infra-red radiation (7350 A.). Many other light-sensitive growth phenomena have been shown to exhibit this type of response to successive exposure to red light and infra-red radiation. Subjecting the chrysanthemum to low temperatures during an inductive dark period may markedly reduce its effect. Initiation of inflorescence primordia may be retarded indefinitely, and in some varieties a marked terminal, vegetative rosette forms. If initiation occurs, the plant may behave as if it were in long-day conditions, that is to say, bracts and capitulum are formed but floret initiation is suppressed. If floret initiation occurs, the number of disk florets is reduced as in long-day conditions. Low temperature during a preceding long-day period may also affect the response to inductive photoperiods; in some varieties break bud formation occurs at favourable temperatures in short days following exposure to low temperature in long days.

Photoperiod regulates numerous other phenomena in plants, including dormancy in woody species. Dr. P. F. Wareing (University of Manchester) showed that in many species the onset of dormancy occurs in response to short photoperiods, the stimulus being perceived (as in the flowering response) by the leaves. The resumption of growth normally requires exposure to low temperatures, but is photoperiodically controlled in some species; leafless seedlings of beech will grow out in long photoperiods and, in this instance, the stimulus is perceived by the buds. Some species, including birch, show an interaction between chilling and day length; unchilled seedlings will only resume growth in long photoperiods, but chilled seedlings elongate in any day length. Sensitivity to photoperiod is also exhibited by seeds of birch. At $15^{\circ} \mathrm{C}$. the percentage of seeds germinating is increased in long days; this is a true photoperiodic response, being controlled primarily by the length of the dark period. The interaction of temperature with photoperiod was again stressed since at $20^{\circ} \mathrm{C}$. germination occurs in response to a single exposure to light. Birch seeds thus show the typicel red/infrared response of light-sensitive seeds at high temperatures and a photoperiodic response at lower temperatures. After chilling, the seeds are no longer light-sensitive. Experiments carried out to elucidate the mechanism of light-sensitivity suggest the presence of an inhibitor in the seed coat, which undergoes destructive oxidation since, whereas the excised embryo shows no photoperiodic response and has a low oxygen requirement, the percentage of whole seeds germinating in the dark is increased by leaching, by slitting the seed, and by increasing the oxygen concentration (slit or scratched seeds only).

Mr. 1. H. Williams (University of Nottingham) demonstrated the importance of photoperiod as a factor controlling growth and development in the raspberry 'Malling Promise'. Under natural conditions, the biennial cane grows vegetatively in the first summer ; as the days shorten in the autumn, the cane becomes dormant and flower primordia are initiated in the axillary buds. In the second summer these mixed fruiting laterals grow out and a replacement shoot arises at the base of the two-year old cane. Initiation of flower primordia occurs during falling temperatures and shortening days and experiments in growth rooms have demonstrated the marked interaction between temperature and day length; at $10^{\circ} \mathrm{C}$. initiation occurs in all day lengths, but at higher temperatures primordia are initiated only in short days. The lateral shoots remain dormant in subsequent long days unless chilled at $3 \cdot 5^{\circ}$ C. for six weeks; the resumption of growth in this species is not, therefore, photoperiodically controlled. The process of breaking dormancy can be separated from that of flower initiation by exposing the plants to $3.5^{\circ} \mathrm{C}$. in the dark without previous exposure to short days or cool temperatures, when vegetative laterals will grow out in subsequent conditions of long days and high temperatures. Mr. Williams directed attention to the effect of the physiological age of the shoot on its response ; following exposure to inductive conditions (short days at $10^{\circ} \mathrm{C}$.) for 
eight weeks, shoots of 12 nodes remained vegetative and continued growth on the main axis only ; 15-node plants developed flowers after six to eight weeks, 20 -node plants after three weeks, and 30-node plants after one week of such treatment.

The observed interactions between temperature and photoperiodic behaviour link the three papers. In chrysanthemum inductive photoperiods may be ineffective at, or when preceded by, low temperatures ; dormant seedlings of birch are no longer sensitive to photoperiod after chilling; birch seeds are lightsensitive at $20^{\circ}$ C., photoperiodically sensitive at $15^{\circ} \mathrm{C}$, and will germinate in the dark after exposure to low temperature; raspberry canes are photoperiodic at $15 \cdot 5^{\circ} \mathrm{C}$. but will initiate flower primordia in any day length at $10^{\circ} \mathrm{C}$. The various types of interaction are of considerable interest, and their mechanism merits further study.

The afternoon session was opened by a paper by Dr. van der Veen (Philips Research Laboratories, Eindhoven, Holland) on the influence of coloured light. Dr. van der Veen emphasized the technical difficulties of obtaining light of high spectral purity at intensities sufficiently great to maintain growth, and demonstrated that a very small amount of contamination at certain wave-lengths may be important. Blue light with a small amount of near infra-red may cause internode elongation, wherees pure blue light results in internode shortening; a small amount of infra-red in red light is less important because of the red/infra-red antagonism in many species. Dr. van der Veen emphasized the complexity of the reaction of plants to coloured light, pointing out that response may vary according to the species and to the method of application. The effectiveness of a flash of red light in the middle of a long dark period in promoting flowering in long-day plants and inhibiting flowering in short-day plants is well established. However, the long-day plant Hyocyamus niger will not flower in long days in red light alone, but will flower in the same day length when a small amount of near infrared radiation is added. Variations between species was illustrated by reference to leaf expansion, which is promoted in many species by red light but occurs only in blue light in Mirabilis, and to internode extension, which may be increased (tomato) or decreased (pea) by exposure to red light.

Practical plant irradiation was the subject of the final paper by Mr. A. E. Canham (Electrical Research Association), who discussed the relative merits of several standard types of lamp for various applications in horticulture. Lamps may be used in insulated dark structures to replace daylight or in glasshouses, as a supplement to natural daylight when the light intensity is low; different factors must be taken into consideration in the two methods of irradiation. When daylight is replaced entirely, both formative and photosynthetic effects must be considered; the maximum rate of photosynthesis occurs in red light but the formative response to wave-length varies widely with species and, with the present limitation of knowledge, radiation in all visible wave-lengths, with no undue preponderance in one band and with little near infra-red radiation, is recommended. 'Daylight' fluorescent lamps have been found to be most satisfactory in producing 'normal' growth but, because of their low intrinsic brightness, large numbers are required. The formative effects of lamps are less important for supplementary irradiation since daylight will tend to balance the lamp effect, but an unduly high proportion of red or near infra-red may result in elongation and/or leaf epinasty in some species. Providing the formative effect is not unfavourable, economic and practical considerations largely determine the choice of lamp; of the lamp types currently available the high-pressure mercury vapour lamp is generally recommended.

The symposium concluded with a film by Mr. A. G. Sparkes (West End Nurseries, Angmering) showing the use of photoperiodic regulation in practice to achieve flowering of chrysanthemums all the year round. With suitable schedules of lighting, and shading with black cloth, flowers may be cut in every week of the year.

The papers presented at the symposium will be published in Scientific Horticulture. D. VINCE

\title{
A FLORA OF EUROPE
}

\author{
By Prof. N. A. BURGES and DR V. H. HEYWOOD \\ University of Liverpool
}

$\mathrm{H}$ ISTORICALLY, plant taxonomy has tended to pass through phases of local exploration, consolidation and regional synthesis, occasionally the whole cycle being repeated at a higher level of knowledge. In Europe, however, taxonomy has never attained this overall regional view. On the other hand, no other continent or part of the world, with a flora comparable in number of species, displays such a diversity of partial Floras, each with independent criteria and more or less strict adherence to national or local boundaries.

With the exception of some areas in Spain and the Balkans, few basic systematic novelties await discovery and description in Europe. Individually, most European countries can now claim that the descriptive-geographical taxonomy of their flora has been satisfactorily achieved. With the new tools of cytogenetics, ecology and biometrics and like dis. ciplines, and with the new ideas inspired by modern genetical and evolutionary theory, much of the work now undertaken by European taxonomists on their own floras is of an experimental or evolutionary nature. Descriptive taxonomy is largely limited to that of the colonies or other territories administered by their parent countries.

There are signs that this local analysis, in the absence of compensating synthesis, may prove detrimental to taxonomy as a whole. The position is such that to answer almost any question on European taxonomy the specialist has to refer to upwards of fifty Floras and countless papers and then synthesize the resultant information. This is time-consuming enough for the professional taxonomist who knows the literature well and who has it available (and 